\title{
Measuring household vulnerability to climate-induced stresses in pastoral rangelands of Kenya: Implications for resilience programming
}

\author{
Francis EO Opiyo ${ }^{1,2^{*}}$, Oliver V Wasonga ${ }^{1,3}$ and Moses M Nyangito ${ }^{1}$
}

\begin{abstract}
This study uses statistical and econometric tools to measure households' vulnerability in pastoral rangelands of Kenya. It considered 27 socio-economic and biophysical indicators obtained from 302 households' in-depth interviews to reflect climate vulnerability components: adaptive capacity, exposure and sensitivity. The theoretical framework used combines exposure and sensitivity to produce potential impact, which was then compared with adaptive capacity in order to generate an overall measure of vulnerability. Principal component analysis (PCA) was used to develop weights for different indicators and produce a household vulnerability index (HVI) so as to classify households according to their level of vulnerability. In order to understand the determinants of vulnerability to climate-induced stresses, an ordered probit model was employed with predictor variables. The results show that $27 \%$ of households were highly vulnerable, $44 \%$ were moderately vulnerable and $29 \%$ of households were less vulnerable to climate-induced stresses. Factor estimates of the probit model further revealed that the main determinants of pastoral vulnerability are sex of household head, age of household head, number of dependents, marital status, social linkages, access to extension services and early warning information, complementary source of income, herd size and diversity, herd structure, herd mobility, distance to markets, employment status, coping strategies and access to credit. Therefore, policies that address these determinants of vulnerability with emphasis on women's empowerment, education and income diversifications are likely to enhance resilience of pastoral households.
\end{abstract}

Keywords: Climate change; Pastoralists; Principal component analysis; Resilience; Vulnerability

\section{Background}

Vulnerability, commonly defined as the propensity or predisposition to be adversely affected, has been studied as a composite of adaptive capacity, sensitivity and exposure to hazards (Adger and Kelly 1999; Kelly and Adger 2000; McCarthy et al. 2001; Intergovernmental Panel on Climate Change IPCC 2001; Adger 2006; Füssel 2007; Paavola 2008; Yuga et al. 2010). Adaptive capacity is the ability of people to cope with or adjust to the changing context and is explained by socio-economic indicators. Sensitivity is

\footnotetext{
* Correspondence: francis.opiyo@undp.org

'Department of Land Resources Management and Agricultural Technology, University of Nairobi, P.O. Box 29053, Kabete, Nairobi 00625, Kenya

${ }^{2}$ Dryland Development Centre, United Nations Development Programme (UNDP), United Nations Office in Nairobi, P.O. Box 30552, Nairobi, Gigiri 00100, Kenya

Full list of author information is available at the end of the article
}

the ability of a system to be affected, and exposure is the incidences of events (Kasperson et al. 1995; Adger 2006; Paavola 2008). Vulnerability is thus comprised of risks or a chain of risky events that households confront in pursuit of their livelihoods, the sensitivity of livelihood to these risks, the response or options that households have for managing these risks and finally the outcomes that describe the loss in wellbeing (Turner et al. 2003).

On the other hand, resilience is seen as the ability to self-organize, learn and adapt to risk hazards (Carpenter et al. 2001; Turner et al. 2003). The United Nations International Strategy for Disaster Reduction (United Nations International Strategy for Disaster ReductionUNISDR 2009) defines resilience as the transformative process of a household or community exposed to hazards to resist, absorb, accommodate and recover from hazards 
in a timely and efficient manner. Turner et al. (2003) and Gallopin (2006) define hazards as threats to a system and comprised of stressors. For simplicity, the term stress is used in this study to denote a continuous or slowly increasing pressure (in this case drought), commonly within the range of normal variability. However, over the last decades, most of the scientific literature and discourses on vulnerability have concentrated on contributing to theoretical insights or measurements at the regional or national scale, with selected indicators for each region, and identifying resilience-building strategies that have implication for national and regional planning (Brooks et al. 2005; Füssel 2007; Hinkel 2011). Yet, micro-level vulnerability analysis is an essential prerequisite for local-level planning and prioritization of resilience planning and strategies especially among the natural resource-dependent communities at risk to projected climate variability and changes (Callaway 2004; Fraser et al. 2011).While there is no superior scale of climate vulnerability analysis, recent studies by Yuga et al. (2010) and Marshall et al. (2014) have confirmed that micro-level analyses have hitherto largely been overlooked in favour of ecosystemscale studies of biophysical vulnerability.

As observed by Deressa et al. (2008), climate change vulnerability analysis ranges from local or household level (Adger 1999) to the global level (Brooks et al. 2005; Intergovernmental Panel on Climate Change IPCC 2014). However, the choice of scale is dictated by the objectives, methodologies and data availability. This present study focused on household-level vulnerability analysis. After all, it is by understanding, planning for and adapting to a changing climate that individual households can take advantage of opportunities to reduce risks associated with climate-induced stresses (Madu 2012). Similarly, Klein et al. (2007) observed that vulnerability analysis to climate change is needed at the level that would enable policy makers to tackle climate change challenges with the precision that is necessary, particularly in the arid and semi-arid regions of Africa. Previous studies by Brooks et al. (2005) and Intergovernmental Panel on Climate Change IPCC (2012) concluded that the majority of households are particularly vulnerable to the impacts of climate change in the arid and semi-arid regions. Although the causes of such vulnerability are multi-dimensional, they are primarily due to widespread poverty, food insecurity, recurrent droughts, land degradation, inequitable land distribution and overdependence on rain-fed agriculture (Notenbaert et al. 2013; Lo'pez-Carr et al. 2014). Some of the other common factors also postulated to determine adaptive capacity, and therefore influence vulnerability at the household level, include access to resources, markets and infrastructure; household structure, gender, education and age; farm size; income and income diversity; access to community-based organizations, information, credit facilities, savings and loans; and health status among others. Stringer et al. (2009) argued that though all households in a community are exposed to risks associated with climate change and could potentially be rendered vulnerable, the poorer households are the most at risk of adverse impacts of climate variability and change. That notwithstanding, the proportion of households vulnerable to extreme weather events is perceived to be increasing in arid environments of eastern Africa, especially in Kenya, and there is an uncertain degree to which the population or the system is becoming susceptible and unable to cope with hazards and stresses, including the effects of climate change.

In Kenya, there is a consensus that projected climate change will worsen food security, mainly through increased extremes and temporal or spatial shifts (Eriksen and O’Brien 2007; Herrero et al. 2010; Sherwood 2013). In fact, there is considerable potential impact of these global drivers of change on the production systems and resource-poor households who depend on them. Studies by Kabubo-Mariara (2009) and Silvestri et al. (2012) revealed that extreme weather events such as prolonged dry spells and intense rainfall are already affecting rural communities in parts of arid and semi-arid lands (ASALs) of Kenya. At present, nearly 30\% of the total human population resides in the ASALs, which cover approximately $88 \%$ of the country's land mass, and hold almost $70 \%$ of the total national livestock herd. However, large proportions of pastoralists who reside in ASALs are believed to be at risk of food production deficit, with potential declines in pasture and water availability (Opiyo et al. 2011), all exacerbated by extreme climate events. Hence, the purpose of this paper is to identify the determinants of vulnerability and measure micro-level vulnerability of pastoralists in arid rangelands of Kenya. The vital information that is obtained from household-level vulnerability analysis is presently lacking in national and regional level assessments. Deressa et al. (2008), Pearson et al. (2008) and Sherwood (2013) show that vulnerability contexts are diverse for different multiple spatial scales, and therefore this approach can contextualize how climate variability and change affect pastoralist livelihoods.

This study was thus carried out to investigate households' vulnerability to climate variability and change to climateinduced stresses in a case study of a pastoralist rangeland of Kenya. The study identifies some of the determining factors for vulnerability based on certain household social, economic and environmental (biophysical) characteristics. The household was selected as the main unit of analysis because major decisions about adaptation to climateinduced stresses and livelihood processes are taken at that level (Thomas 2008). Nevertheless, households are connected to the wider community, which can greatly influence their decision-making processes in relation 
to use of particular productive resources. The findings of this study can therefore be useful for targeting interventions, priority setting and resource allocations at micro-level. Complemented with studies analysing climate change impacts and findings from country-level adaptive capacity, governmental policy can be informed. At the same time, the uncertainty associated with climate variability and change demands an approach that prepares rural households without relying on detailed climate projections. The study therefore focused on the adaptive capacity of households for wider resilience programming. Moreover, the findings would assist in resources allocation and determination of resilience investment opportunities that are likely to increase the adaptive capacity of the vulnerable households. The findings in particular suggest potential avenues for research that may further enhance understanding of household vulnerability to climate stresses in the arid rangelands of Kenya.

\section{Study area}

The study was conducted in Turkana County, northwestern rangelands of Kenya (Figure 1). The county lies between longitude $34^{\circ} 30^{\prime}$ and $36^{\circ} 40^{\prime} \mathrm{E}$ and latitude $1^{\circ} 30^{\prime}$ and $5^{\circ}$ $30^{\prime} \mathrm{N}$, covering an area of $77,000 \mathrm{~km}^{2}$ with an estimated human population of 855,399 according to the 2009 Kenya housing and population census report. The county is one of the poorest in Kenya with an estimated $87.5 \%$ of the population living below the absolute poverty line (Kenya National Bureau of Statistics KNBS 2013). In Lokichoggio, Kakuma and Oropoi divisions where the household survey was undertaken, poverty is exacerbated by the harsh environment, poor infrastructure and low access to basic services, in addition to other underlying causes of poverty that are experienced in northern Kenya. About 96\% of the study area falls into arid and very arid eco-climatic zones (Jaetzold and Schmidt 1983). In the study area, because of aridity, managing short-term climatic fluctuations as well as adapting to long-term changes is critical in sustaining livelihoods. According to the most recent household economy approach assessments, pastoralism is the predominant livelihood accounting for over $55 \%$ of the population; $15.6 \%$ agro-pastoral, $8 \%$ fisher folks and $8.4 \%$ are in the urban/peri-urban areas (Household Economy Approach HEA 2012).

Rainfall in the study area exhibits a bimodal pattern, and distribution is unreliable and erratic in both space and time, with an average annual rainfall of $120 \mathrm{~mm}$ in the east to over $200 \mathrm{~mm}$ in the northwest. Figure 2 shows the annual rainfall variability of the study area. The main rainy season at local level between March 1950 and July 2012 the study area received very low and variable rain. In the past decades, major widespread drought events were experienced in 1980 to 1984,1990 to 1995,1999 to 2000, 2008 to 2009 and 2010 to 2011 within the study area. The last drought crisis in the Horn of Africa is estimated to have affected over 13 million people, including 3.75 million Kenyan, especially in the ASALs (UN-OCHA 2011). The daily temperature ranges are extremely high with an average daily range varying between $24^{\circ} \mathrm{C}$ and $38^{\circ} \mathrm{C}$ with a mean of $30^{\circ} \mathrm{C}$. The vegetation in this area is mainly scattered Acacia bush and a cover of annual herbaceous plants. The density of the woody plants such as Acacia reficiens and A. mellifera increases on hilly ground.

The study area is inhabited by the Turkana pastoralists whose major occupation is extensive livestock production (Watson and van Binsbergen 2008). The livestock species kept include camels, cattle, sheep, goats and donkeys, which have different forage and water requirements and variable levels of resilience during drought episodes. In Turkana, droughts, famine, epidemics and flash floods are also very common occurrences. In most instances, these shocks and stresses are associated with climatic variability and change (Notenbaert et al. 2013). The outcome of these climatic stresses has been high livestock mortality, loss of property, displacement of people and resources conflicts (Schilling et al. 2012). In general, by weakening the productivity and functioning of livelihood resources, climatic stresses aggravate the vulnerability of households dependent on these resources. However, Turkana pastoralists are known to be highly mobile with no fixed residence (McCabe et al. 1988), but their regular patterns of movement often get disrupted by conflicts and disease outbreaks (Hendrickson et al. 1998; Schilling et al. 2012).

\section{Methods}

\section{Data collection}

A total of 302 pastoralist households were selected for interviews a using semi-structured questionnaire to elicit responses between June and July 2012. Systematic purposive sampling was used to select drought-prone divisions in Turkana County which include Lokichoggio, Kakuma and Oropoi. However, the specific kraals (homesteads)/locations where households were selected based on accessibility of the area. Consequently, 10 locations/kraals were selected from which the sample households were selected randomly proportional to population size. Table 1 shows the sampled households from each of the $10 \mathrm{kraals} /$ locations. A semi-structured questionnaire was used to interview the household heads. The questionnaire was divided into the following: demographic and economic household characteristics, livestock and crops production, access to extension services, credit access, hazards occurrence, perception level, adaptation strategies pursued, different coping strategies, level of resilience and other relevant information.

In addition, in situ rainfall and temperature datasets relevant for this study were obtained from Kenya 


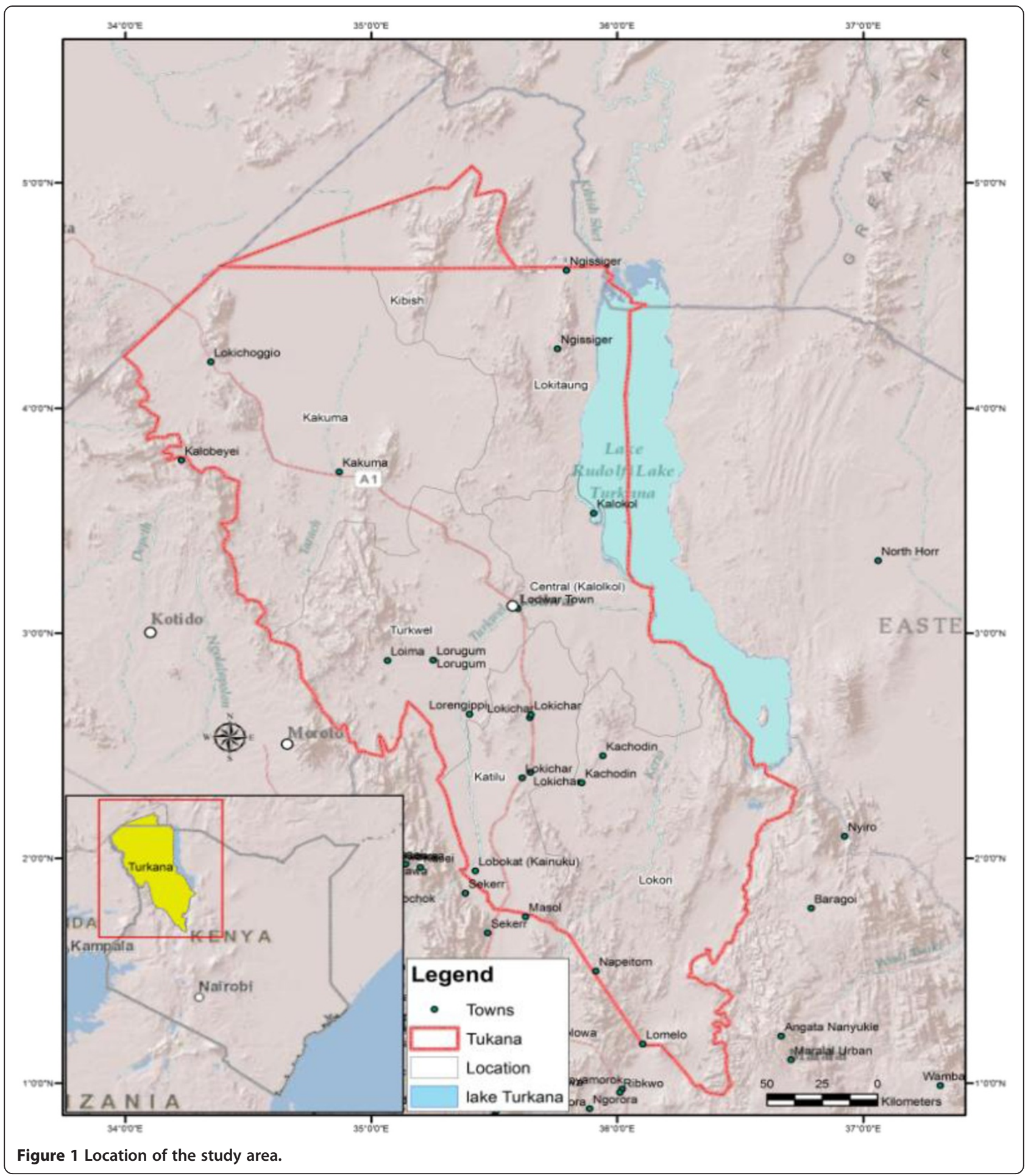

Meteorological Services, National Drought Management Authority (National Drought Management Authority NDMA 2013) and County government officers in Lodwar, Turkana to strengthen some of the study findings. The STATA software was used to analyse the data obtained.

\section{Analysis of households' vulnerability}

There are various ways of analysing vulnerability, namely, socio-economic, biophysical and an integrated approach, which unites both socio-economic and biophysical factors. The socio-economic vulnerability assessment approach focuses on the socio-economic and political status of 


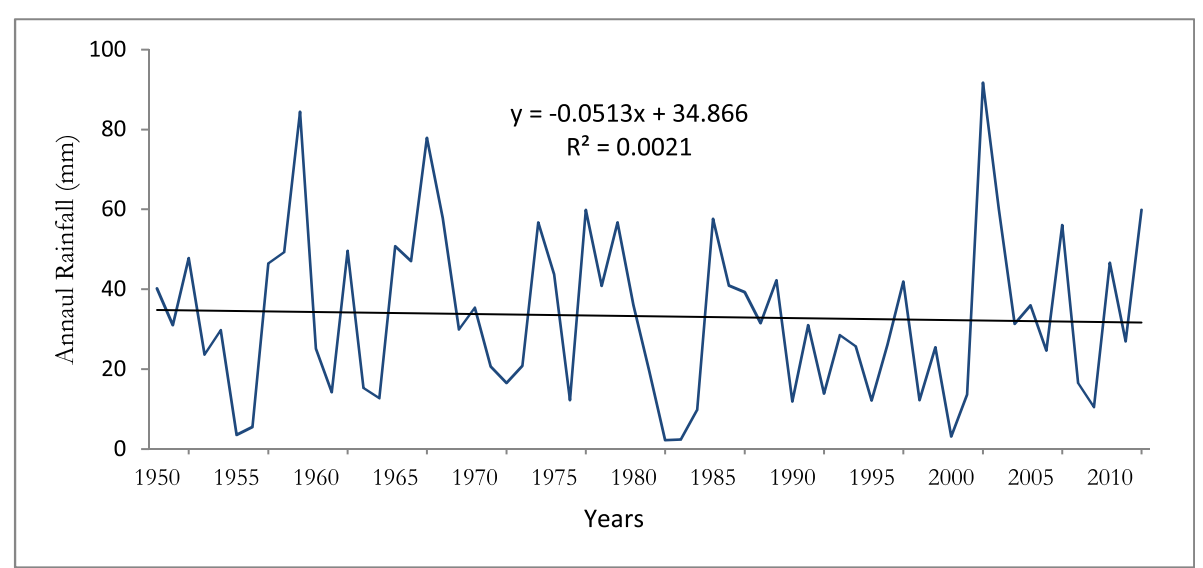

Figure 2 Annual rainfall variability for period 1950 to 2012 in the study area.

individuals or groups. Individuals in a community vary in terms of education, gender, wealth, health status, access to credit, access to information and technology, formal and informal (social) capital and political power, which are responsible for variations in vulnerability levels (Füssel 2007; Deressa et al. 2008). Consequently, vulnerability is considered to be a starting point or a state that exists within a system before it encounters a hazard event (Kelly and Adger 2000). In this regard, vulnerability is shaped by society as a result of institutional and economic changes. The socio-economic approach focuses on identifying the adaptive capacity of individuals or communities based on their internal characteristics. One major limitation of this approach is that it focuses only on variations within society, but in reality, societies vary not only due to socio-political factors but also because of environmental or biophysical factors. The socio-economic approach does not account for the natural resource bases which have the potential to counteract the negative impacts of environmental shocks.

Table 1 Sampled households by Kraal

\begin{tabular}{llll}
\hline Location/Kraals & $\begin{array}{l}\text { Number of } \\
\text { households }\end{array}$ & $\begin{array}{l}\text { Sampled } \\
\text { household }\end{array}$ & $\begin{array}{l}\text { Percentage } \\
\text { of respondent }\end{array}$ \\
\hline Mogila & 1,536 & 20 & 6.62 \\
Lokichoggio & 1,868 & 9 & 2.98 \\
Lopusiki & 649 & 1 & 0.33 \\
Lopwarin & 277 & 11 & 3.64 \\
Songot & 459 & 19 & 6.29 \\
Nanam & 748 & 38 & 12.58 \\
Kakuma & 12,767 & 33 & 10.93 \\
Letea & 4,957 & 56 & 18.54 \\
Kalobeyei & 2,577 & 39 & 12.91 \\
Pelekech & 1,863 & 76 & 25.17 \\
\hline
\end{tabular}

Kraal used herein to refer to a traditional pastoralists village of huts, typically enclosed by a fence. (Source: Authors' compilation).
For example, areas with easily accessible underground water can better cope with drought by utilizing this resource, compared to areas without it (Deressa et al. 2008).

The second commonly used approach is biophysical that attempts to assess the level of damage that a given environmental stress causes on both social and biological systems. It is sometimes known as an impact assessment. The emphasis is on the vulnerability or degradation of biophysical conditions (Liverman 1990). This is a dominant approach employed in studies of vulnerability to natural hazards and climate variability and change (Hewitt 1995). Füssel (2007) identified this approach as a riskhazard approach. The biophysical approach, although very informative, also has a major limitation that assessment of biophysical factors is not a sufficient condition for understanding the complex dynamics of vulnerability. This approach also neglects both structural factors and human agency in producing vulnerability and in coping or adapting to it. The approach overemphasizes extreme events while neglecting root causes and everyday social processes that influence differential vulnerability (Liverman 1990; Hewitt 1995; Pulwarty and Riebsame 1997). The third approach is the integrated vulnerability analysis, which combines both the socio-economic and biophysical factors. This approach includes all the internal state of vulnerability and the external situation. This analytical approach was applied by Madu (2012) in agro-ecological based household vulnerability analysis in Ethiopia and by Deressa et al. (2008) in regionally based vulnerability analysis.

This present study replicates an integrated vulnerability approach to develop vulnerability indices for each household as proposed by Madu (2012) and adopted by Tesso et al. (2012) in Ethiopia. In this research, it is assumed that households with higher adaptive capacity are less sensitive to impacts of climate-induced stresses, thus keeping the level of exposure constant. The integrated assessment approach combines both socio-economic and biophysical 
approaches to determine vulnerability. The vulnerability index development is given as developed by the Intergovernmental Panel on Climate Change IPCC (2012) that vulnerability is seen as the net effect of adaptive capacity (socio-economic) and sensitivity/exposure (biophysical):

Vulnerability $=($ Adaptive capacity $)-($ Sensitivity + Exposure $)$

When the adaptive capacity of the household exceeds that of its sensitivity and exposure, the household becomes less vulnerable to climate change impacts and the reverse is also true. As explained in the foregoing, each set (adaptive capacity, sensitivity and exposure) is composed of different variables. The model specification further looks like

$$
\begin{aligned}
V_{i}= & \left(A_{1} X_{1 J}+A_{2} X_{2 J}+\cdots+A_{2 n} X_{n J}\right) \\
& -\left(A_{n+1} Y_{1 J}+A_{n+2} Y_{2 J}+\cdots+A_{n+n} X_{n J}\right)
\end{aligned}
$$

where $V_{i}$ is the vulnerability index, while $X_{\mathrm{s}}$ are elements of adaptive capacity, and $Y_{\mathrm{s}}$ are elements of exposure and sensitivity. The values of $X$ and $Y$ are obtained by normalization using their mean and standard errors. For instance, ${ }^{X_{I J}}=\left(X_{I J}-X_{1 *}\right) /_{S^{1 *}}$, where $X_{1 j^{*}}$ is the mean of $X_{1 j}$ across the different households, $S_{1}{ }^{*}$ is its standard deviation. $X_{1}$ is the principal component result of factors. In this regard, the first principal component of a set of variables is the linear index of all the variables that captures the largest amount of information common to all the variables. The whole matrix of variables of adaptive capacity $\left(X_{i j}\right)$ and variables of exposure and sensitivity $\left(Y_{i j}\right)$ appears as follows:

$$
X_{i j} /_{Y_{i j}}=\left(\begin{array}{l}
\left(X_{11}+X_{12}+\cdots+X_{2 n}\right)-\left(Y_{11}+Y_{12}+\cdots Y_{2 n}\right) \\
\left(X_{m 1}+X_{m 2}+\cdots+X_{m n}\right)-\left(Y_{m 1}+Y_{m 2}+\cdots Y_{m n}\right)
\end{array}\right)
$$

The $i$ and $j$ in the foregoing notation imply the number of rows (in this case is the 302 individual households) and the number of columns (27 variables of adaptive capacity, exposure and sensitivity). In Equation 4, the $A_{\mathrm{s}}$ is the first component score of each variable computed using principal component analysis (PCA) in STATA. Finally, the vulnerability index of each household is obtained using Equation 4 as follows:

$$
V_{i}=\left(\begin{array}{l}
A_{1} \\
A_{12} \\
A_{n+n}
\end{array}\right) \times\left(\begin{array}{c}
\left(X_{11}+\cdots+X_{2 n}\right)-\left(Y_{11}+\cdots+Y_{2 n}\right) \\
\left(X_{m 1}+\cdots+X_{m n}\right)-\left(Y_{m 1}+\cdots+Y_{m n}\right)
\end{array}\right)
$$

In calculating the direction of relationship in vulnerability indicators (that is, their sign), a negative value was assigned to both exposure and sensitivity. The justification is that households which are highly exposed to climate shocks are more sensitive to damage, assuming constant adaptive capacity. The implication is that a higher net value indicates lesser vulnerability and vice versa. However, in creating the indices, the scale of analysis is important. As noted by Tesso et al. (2012) from Deressa et al. (2008), vulnerability analysis ranges from local or household level to the global level (Brooks et al. 2005). The choice of scale is dictated by the objectives, methodologies and data availability. In this study, the households were classified into three categories based on the value of their vulnerability index, which puts households into highly vulnerable, vulnerable and less vulnerable categories. However, the index computed is not based on the thresholds or presents an absolute value. It is a relative measure, representing the households' own perception of how they have been coping in the past compared to other households.

\section{Factors influencing household vulnerability}

Notenbaert et al. (2013) note that many factors contribute to vulnerability, and these factors undermine capacity for self-protection, block or diminish access to social protection, delay recovery or expose some households to greater or more frequent hazards than other households. The analysis was performed using ordinal logistic regression analysis. The ordinal logit model is used when the outcome variable is categorized in an ordinal scale, as in this case where vulnerability is ordered as (1) highly vulnerable, which implies households for whom the difference between adaptive capacity and sensitivity/exposure is significantly negative; (2) moderately vulnerable, which means that households for whom the difference between adaptive capacity and sensitivity/exposure is nearly zero; and (3) less vulnerable, which means that the difference between adaptive capacity and exposure/sensitivity is significantly positive. In this study, sensitivity of households to climateinduced stresses is represented by its associated impacts, i.e., shortage of food, loss of water and pasture resources and conflicts faced by those households. In the case of exposure, since all households are assumed to be located in the same environment, exposure is almost uniform across the respondents residing in the study area.

This model is particularly useful in that it can show movement between vulnerability groups, explaining who moves in and out of vulnerability. Following Greene (1997), the reduced form of the ordinal logit model is given as

$$
Y_{j}^{*}=X_{j}^{I} \beta+U_{I j}
$$

where $Y$ is the level of vulnerability and involves ordered outcome, that is, $Y=1$ was given to households that have a high level of vulnerability as observed by the negative value of adaptive capacity minus sensitivity/exposure; 
$Y=2$ was given to households having adaptive capacity nearly equal to their sensitivity/exposure; and $Y=3$ was given to households having their adaptive capacity exceeding their sensitivity and exposure. $Y^{*}$ is the given state of vulnerability. The $X_{i j}$ are the explanatory variables determining vulnerability level. The independent variables included in the model were sex and age of the household head, experience in the study area, household size and education level of the household head, dependency, marital status, social linkages and visits by extension officers, access to early warning information, non-farm income, herd size, herd structure, access to markets, property regimes, access to remittances, employment, coping strategies, herd diversity, credit access, herd mobility, climate change, experience in increased temperature, drought, floods, and wind, and natural hazards encountered in 5 years. $\beta_{\mathrm{S}}$ are parameters estimated and $U_{i j}$ is the disturbance term. $Y^{*}$ is unobserved, but what was observed in this study is

- $Y=1$ if $Y^{*} \leq \mu 2$

- $Y=2$ if $\mu 2<Y^{*} \leq \mu 3$

- $Y=3$ if $\mu 3<Y^{*}$

Given the cumulative normal function $\Phi\left(\beta^{\prime} x\right)$, the probabilities can be shown, thus,

- $\operatorname{Prob}[y=1$ or highly vulnerable $]=\Phi\left(-\beta^{\prime} x\right)$,

- Prob $[y=2$ or neutral level of vulnerability $]=\Phi$ $\left(\mu 2-\beta^{\prime} x\right)-\Phi\left(\mu 3-\beta^{\prime} x\right)$

- Prob $[y=3$ or less vulnerable $]=1-\Phi\left(\mu 3-\beta^{\prime} x\right)$

\section{Results}

\section{Hazards reported by households}

The results show that $49 \%$ of households experienced drought over the past three decades, with $27.1 \%$ of the respondents reporting livestock disease outbreak, 19\% mentioning cross-border inter-community conflicts and $4 \%$ citing riverine flash floods as the main hazard (Table 2). However, it was difficult for the respondents to differentiate between threats and hazards, which required clarification of the differences. Drought events were reported to be frequent hazards in the area and had devastating impacts on household livelihoods, pasture and water, which escalates the area's chronic conflicts, insecurity and food insecurity.

Inter-community and ethnic conflict related to scarce grazing land and water resources was reported to have increased inter-tribal animosity, often resulting in armed violent conflicts, which are predatory in nature and much more destructive. Households stated that violent conflicts regularly lead to heavy losses of lives and livelihoods, undermining human and livestock population mobility, as well as development efforts. Study findings show that outbreaks of peste des petit ruminants (PPR) locally referred to as lomoo is considered as the major hazard, having the highest impact on small ruminants compared to other endemic livestock diseases in the area. On further probing with community animal health workers and veterinary officers, based on the symptoms described by the pastoralist respondents, other diseases were identified as etome (mange), emadang' (worms infestation), lukoi (contagious caprine pleuropneumonia), lomeri (lump skin disease), lokichum (heart water), etune (sheep/goat pox), lotorebwo or lokipi (trypanosomiasis), logooroi (hemorrhagic septicaemia) and loukoi (contagious bovine pleuropneumonia).

\section{Socio-economic and biophysical vulnerability}

The social and economic variables contributing to vulnerability are summarized in Table 3 . Findings show that more than $80 \%$ of the respondents had no basic primary education, while the majority are not able to read and write. This in turn reduces a household's ability to understand climatic information, access market and early warning information. Data on household size showed that $64 \%$ of those interviewed had more than five persons, with $43 \%$ respondents reported more than five dependents. Whereas the sex of the household head is likely to be critical for climate adaptation, the study revealed that more than $50 \%$ of households are headed by females. In addition, $54 \%$ of the respondents indicated that they do not have access to livestock extension services. The results imply that the vulnerability level of households to the frequently occurring climate-induced stresses is largely determined by gender and education level of the household head in the study area.

Table 2 Hazards identified by respondents

\begin{tabular}{lllc}
\hline Hazard & Description of hazards & Number of respondents & Percentage of respondents \\
\hline Floods & Flash floods along ephemeral rivers & 13 & 4.3 \\
Droughts & Widespread frequent droughts & 148 & 42 \\
Disease outbreak & Livestock diseases outbreak are common & 27.1 \\
Others i.e. conflicts, fire & Inter-community conflicts along the borders over resources & 59 & 19.5 \\
\hline
\end{tabular}

United Nations (2004) defines a 'hazard' broadly as "a potentially damaging physical event, phenomenon or human activity that may cause the loss of life or injury, property damage, social and economic disruption or environmental degradation". (Source: Authors' compilation). 
Table 3 Social, economic and environmental indicators and their effect on vulnerability level

\begin{tabular}{|c|c|c|}
\hline Hypothesized variables & Percentage & Influence on vulnerability \\
\hline \multicolumn{3}{|l|}{ Social vulnerability variables } \\
\hline Sex of HH head: female-headed & 50.7 & + \\
\hline Age of $\mathrm{HH}$ head: $50+$ years & 26.6 & - \\
\hline Experiences in the area: less than 5 years & 7.9 & + \\
\hline HH size: more than 5 persons & 64.6 & - \\
\hline Educational level: no primary education & 80.1 & + \\
\hline Dependents: more than 5 persons & 43.8 & - \\
\hline Marital status: single (including divorced and widowed) & 29.5 & + \\
\hline Linkages: having no social linkages & 25.8 & - \\
\hline Visit by extension officers: no access to extension services & 54.3 & + \\
\hline Access to early warning information: no access to the information & 74.8 & + \\
\hline \multicolumn{3}{|l|}{ Economic vulnerability variables } \\
\hline Non-farm income: have no non-farm income & 35.5 & - \\
\hline Herd size: own less than 2 TLUs & 18.3 & + \\
\hline Herd structure: no milking herd & 72.8 & + \\
\hline Distance to market: more than $10 \mathrm{~km}$ away & 39.4 & - \\
\hline Property regime: own private land & 8.6 & - \\
\hline Access to remittances: no cash transfers & 58 & + \\
\hline HH employed: no member of $\mathrm{HH}$ employed & 88.1 & + \\
\hline HH coping strategies: more than 2 coping strategies & 92.1 & + \\
\hline Livestock diversity: less than 2 livestock species & 45.4 & - \\
\hline Credit access: having no access to credit at all & 77.8 & + \\
\hline Mobility: able to move livestock freely & 67.9 & - \\
\hline \multicolumn{3}{|l|}{ Environmental vulnerability variables } \\
\hline Climate change: experiencing change & 96.7 & + \\
\hline Temperature: experiencing increase & 47.9 & + \\
\hline Drought: noticed increasing events & 3.4 & + \\
\hline Flood: noticed change & 4.1 & + \\
\hline Wind: noticed unusual change & 11.6 & + \\
\hline $\mathrm{HH}$ facing more than 2 hazards in 5 years & 72.5 & - \\
\hline
\end{tabular}

apositive sign indicates that the variable increases vulnerability, while negative sign means it reduces vulnerability. TLU, tropical livestock unit ( $1 \mathrm{TLU}=250 \mathrm{~kg})$. (Source: Estimated from June to July 2012 household survey interviews in Turkana; Authors' compilation).

More than 35.5\% of the households had no diversified income sources and heavily depend on livestock as their source of income. Results show that only a few of the households were practicing dry land crop farming alongside livestock keeping. For the livestock owned, $18 \%$ of respondents had less than two tropical livestock units $\left(\right.$ TLUs $\left.^{\mathrm{a}}\right)$, and $72 \%$ of households had no milking herd during the interview period. Further, the result revealed that about $68 \%$ of households practice seasonal herd mobility and flexible resource use in the study area. The results show that $88 \%$ of households had none of its member formally employed, and $92 \%$ of respondents use more than two coping strategies to survive in this harsh climatic condition, despite the low access to credit, access to remittances and long distances to markets. Other economic concern mentioned was the high formal unemployment opportunities, especially for the youths in Turkana.

Table 3 displays environmental, economic and biophysical factors hypothesized for climate-induced vulnerability. The results show that the sensitivity and exposure to climate variability in terms of those experiencing climate variability (96.7\%) and people facing more than two hazards in 5 years $(72.5 \%)$ have contributed negatively to the vulnerability level of households. Approximately $48 \%$ of the respondents noticed an increase in temperature. However, 
most of the environmental variables increase household's level of vulnerability to climate-induced stresses as indicated by the positive sign.

\section{Measuring household-level vulnerability}

Table 4 presents the result of principal component analysis and its association with the social, economic and environmental variables. The factor scores (weights) of the first principle component analysis was positively associated with the majority of the indicators identified under adaptive capacity, exposure and sensitivity. Holding exposure and sensitivity constant, a negative index shows the household to have relatively lower adaptive capacity when compared to a household with a positive index value and vice versa.

\section{Table 4 Factor score for the first principal component} analysis

\begin{tabular}{|c|c|}
\hline Factors & \multirow{2}{*}{$\begin{array}{l}\text { Factor } \\
\text { Score }\end{array}$} \\
\hline Social vulnerability variables & \\
\hline Sex of HH head: female-headed & 0.22917 \\
\hline Age of $\mathrm{HH}$ head: $50+$ years & -0.25804 \\
\hline Experiences in the area: less than 5 years & -0.02906 \\
\hline HH size: more than 5 persons & -0.29837 \\
\hline Educational level: no primary education & 0.039479 \\
\hline Dependents: more than 5 persons & -0.31599 \\
\hline Marital status: single (including divorced and widowed) & 0.07224 \\
\hline Linkages: having no social linkages & -0.04414 \\
\hline Visit by extension officers: no access to extension services & 0.189862 \\
\hline Access to early warning information: having no access & 0.19573 \\
\hline \multicolumn{2}{|l|}{ Economic variables } \\
\hline Non-farm income: HH with no farm income & -0.34130 \\
\hline Herd size in TLU: own less than 2 TLUs & 0.293813 \\
\hline Herd structure: no milking herd & 0.100562 \\
\hline Distance to markets: more than $10 \mathrm{~km}$ away & -0.15870 \\
\hline Property regime: own private land & -0.06728 \\
\hline Access to remittances: no cash transfers & 0.047677 \\
\hline HH employed: no member of HH employed & 0.095173 \\
\hline HH coping strategies: more than 2 coping strategies & 0.101335 \\
\hline Livestock diversity: less than 2 livestock species & -0.42800 \\
\hline Credit access: having no access to credit at all & 0.178153 \\
\hline Mobility: able to move livestock freely & -0.14718 \\
\hline \multicolumn{2}{|l|}{ Environmental variables } \\
\hline Climate change: experiencing change & -0.02276 \\
\hline Temperature: experiencing increase & 0.081161 \\
\hline Drought: noticed increasing events & 0.164723 \\
\hline Flood: noticed change & 0.039066 \\
\hline Wind: noticed unusual change & 0.259975 \\
\hline HH facing more than 2 hazards in 5 years & -0.06667 \\
\hline
\end{tabular}

Abbreviations: Households (HH), Tropical livestock unit (TLU).
To compute the vulnerability index in Equation 2, indicators of adaptive capacity, which are positively associated with the first principal component analysis, and indicators of sensitivity and exposure, which are negatively associated with the principal component analysis, were used in this study. The variables considered in Equation 2 include sex of the household head, education level, marital status, access to extension services and early warning information, livestock ownership, herd structure, access to cash remittances, household employment status, coping strategies and access to credit. However, for the exposure and sensitivity, all the variables were considered in the analysis. This is because adaptive capacity is considered as positively contributing to the reduction of vulnerability, while exposure and sensitivity are negatively contributing to vulnerability reduction. The larger the factor score the more important is the variable and contributes more to the household's vulnerability.

The households were classified into three categories using the vulnerability index: less vulnerable are households that are in a vulnerable situation but can still cope; moderately vulnerable households are those that need urgent but temporary assistance in case of shock and stresses; and the highly vulnerable are those households that are almost at a point of no return. The result shows that the majority of households fall within the moderately vulnerable category, with $44 \%$ households having an index from -1.00 to 1.00 . The less vulnerable households had an index of 1.1 to 3.0 and constitute $29 \%$, while the highly vulnerable households had an index of -0.9 to -3.0 but are $27 \%$ of the total households sampled (Table 5 and Figure 3). Although there seems to be normal vulnerability index distribution in Figure 3, a keen look at the values showed a slight shift to the left. Statistically, the households' distribution is skewed toward the highly vulnerable in the illustration. In general, the results reveal high and moderate vulnerability levels of the pastoralist households in Turkana.

\section{Determinants of vulnerability}

The majority of highly vulnerable households were headed by females or someone with no primary level of education (Table 6). The highly vulnerable households also had more than five dependents, no access to early warning information, no milking herd and own less than two livestock species, and perceived changes in climate. By contrast, a household is likely to be less vulnerable when they are headed by a male, the household head is literate, not divorced or widowed, when they have access to extension services and early warning information, and own large and mixed-species herds. Similarly, households with access to cash remittances, with a member of the household in formal employment, and those with diverse coping strategies and access to credit facilities are reported to be 
Table 5 Classification of community according to the range of their vulnerability index

\begin{tabular}{llll}
\hline Vulnerability category & Household situation & Vulnerability index & Percentage of households \\
\hline Highly vulnerable & Emergency level HHs & -0.9 to -3.5 & 27 \\
Moderately vulnerable & Needs urgent but temporary external assistance to recover & -1.0 to +1.0 & 44 \\
Less vulnerable & In a vulnerable situation but still able to cope & +1.1 to +3.0 & 29 \\
Total & & & 100 \\
\hline
\end{tabular}

(Source: Computed from household questionnaire interviews in June to July 2012).

less vulnerable to climate extremes. The results suggest that because of scarce resources during extreme climate events, households with high number of dependents and without any other livelihood diversification activities are likely to be more vulnerable than households with complementary sources of income and less dependents.

As shown in Table 6, the majority of households in the moderately vulnerable category are the ones with less than 5 years' experience, either divorced or widowed household heads, household heads with no social linkages, household heads with no access to extension services, households who own less than two TLUs, own private lands, households which do not received any cash remittances, household heads with more than two coping strategies, households who practice mobility and are able to move freely with their livestock herd, and perceive climatic changes in the area.

The results of the ordered logistic regression model for all the single predictors' variables influencing a household's vulnerability are summarized in Table 7. A number of variables were statistically significant at $1 \%$ and $5 \%$ levels of significance and were important in influencing households' vulnerability to climate-induced stresses. The variables that showed significant influence on vulnerability include gender of the household head, age of the household head, size of the household, number of dependents, marital status, access to extension services and early warning information, complementary sources of income, herd diversity and structure, coping strategies and access to credit.

The higher odds ratios computed for age of the household head, household size, dependents, complementary income sources, herd diversity and mobility imply that these factors have more effects on the households' vulnerability level. But it should be noted that majority of the sampled population derived their means of subsistence from nomadic pastoral production system which are weather sensitive and therefore absence of non-agricultural income sources (salary or wages labour) which are not weather sensitive would be a significant determinant on vulnerability level as reflected in the odds ratio figures. Herd diversity and mobility allow households to spread risk and pursue various coping strategies. Herd mobility was observed to be a significant (at 5\%) determinant of households' vulnerability to climate variability and change.

From the ordered regression results, $75 \%$ of femaleheaded households are more likely to be vulnerable to climate-induced stresses and shocks compared to the male-headed households. This might be because femaleheaded households normally face gender discrimination with respect to resources, rights, education, income and economic opportunities. Household age was also an

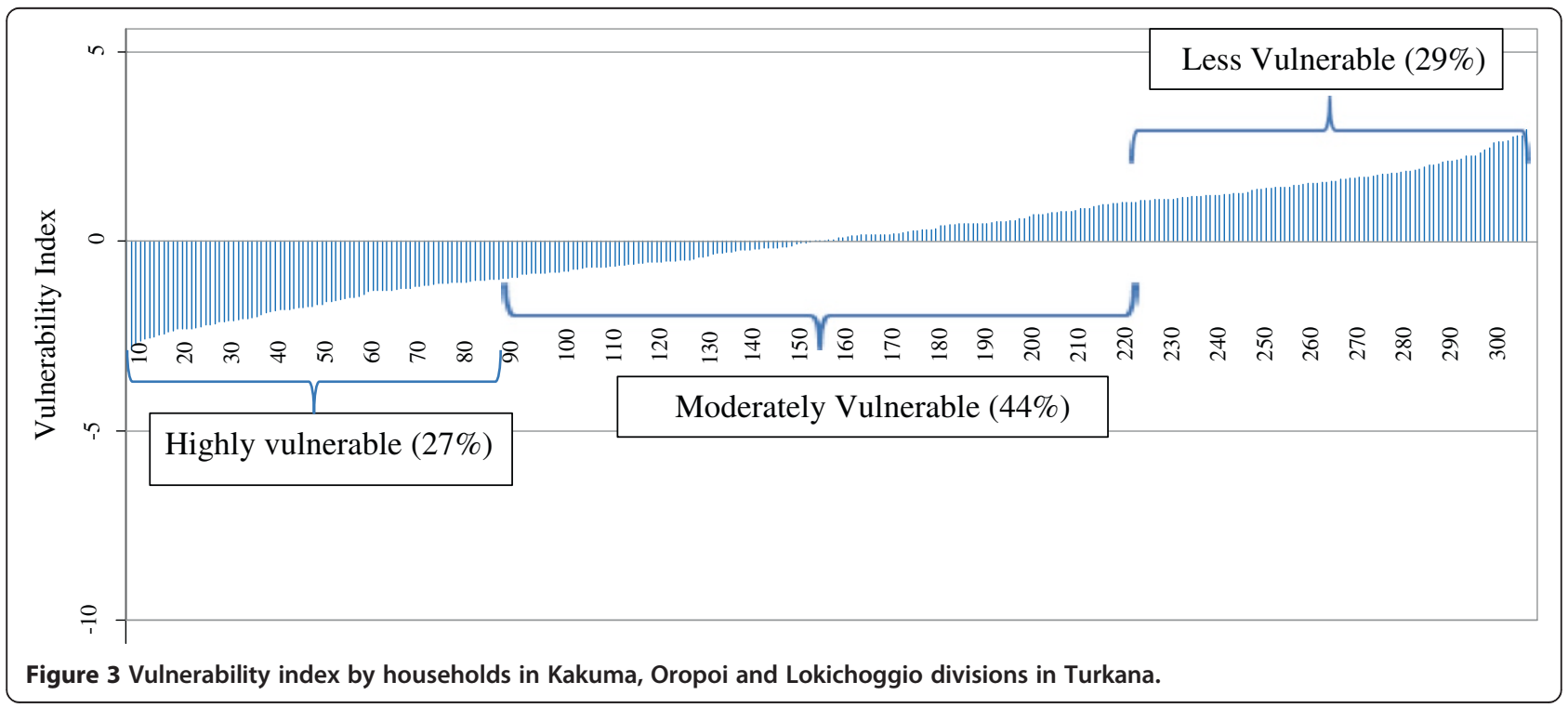


Table 6 Statistical description of model variables by vulnerability category

\begin{tabular}{|c|c|c|c|}
\hline \multirow[t]{2}{*}{ Vulnerability variables } & \multicolumn{3}{|c|}{ Vulnerability category } \\
\hline & Less vulnerable & Moderate vulnerable & Highly vulnerable \\
\hline Sex of HH head: female & $67(44 \%)$ & $62(20 \%)$ & $24(45 \%)$ \\
\hline Age of $\mathrm{HH}$ head: $50+$ years & $6(41 \%)$ & $33(34 \%)$ & $35(25 \%)$ \\
\hline Experiences in the area: less than 5 years & $10(16 \%)$ & $10(44 \%)$ & $4(4 \%)$ \\
\hline HH size: more than 5 persons & $27(8 \%)$ & $92(22 \%)$ & $76(42 \%)$ \\
\hline Educational level: no primary education & $72(45 \%)$ & $107(5 \%)$ & $63(55 \%)$ \\
\hline Dependents: more than 5 persons & $10(47 \%)$ & $58(41 \%)$ & $59(33 \%)$ \\
\hline Marital status: single (including divorced and widowed) & $31(42 \%)$ & $41(55 \%)$ & $17(46 \%)$ \\
\hline Linkages: $\mathrm{HH}$ with no social linkages & $18(42 \%)$ & $34(52 \%)$ & $26(21 \%)$ \\
\hline Visit by extension officers: no access to extension services & $67(17 \%)$ & $65(39 \%)$ & $32(20 \%)$ \\
\hline Access to early warning information: having no access & $77(14 \%)$ & $100(9 \%)$ & $49(45 \%)$ \\
\hline Non-farm income: $\mathrm{HH}$ with no farm income & $5(47 \%)$ & $43(33 \%)$ & $58(34 \%)$ \\
\hline Herd size in TLU: own less than 2 TLUs & $23(39 \%)$ & $17(44 \%)$ & $4(31 \%)$ \\
\hline Herd structure: no milking herd & $72(30 \%)$ & $97(23 \%)$ & $51(42 \%)$ \\
\hline Distance to market: more than $10 \mathrm{~km}$ away & $20(44 \%)$ & $51(18 \%)$ & $40(27 \%)$ \\
\hline Property regime: own private land & $4(26 \%)$ & $13(46 \%)$ & $9(40 \%)$ \\
\hline Access to remittances: no cash transfers & $58(8 \%)$ & $71(36 \%)$ & $46(30 \%)$ \\
\hline $\mathrm{HH}$ employed: no member of $\mathrm{HH}$ employed & $81(46 \%)$ & $118(15 \%)$ & $67(30 \%)$ \\
\hline HH coping strategies: more than 2 coping strategies & $82(46 \%)$ & $121(50 \%)$ & $66(25 \%)$ \\
\hline Livestock diversity: less than 2 species & $5(35 \%)$ & $57(35 \%)$ & $75(58 \%)$ \\
\hline Credit access: having no access to credit at all & $78(46 \%)$ & $108(33 \%)$ & $49(17 \%)$ \\
\hline Mobility: able to move livestock freely & $42(19 \%)$ & $93(41 \%)$ & $70(32 \%)$ \\
\hline Climate change: experiencing change & $43(23 \%)$ & $59(26 \%)$ & $38(47 \%)$ \\
\hline Drought: noticed increasing events & $4(44 \%)$ & $3(30 \%)$ & $3(21 \%)$ \\
\hline Flood: noticed change & $3(33 \%)$ & 7 (44\%) & $2(29 \%)$ \\
\hline Wind: noticed unusual change & $11(41 \%)$ & $16(25 \%)$ & $7(45 \%)$ \\
\hline $\mathrm{HH}$ facing more than 2 hazards in 5 years & $63(40 \%)$ & 99 (30\%) & $57(26 \%)$ \\
\hline
\end{tabular}

$\mathrm{HH}$, households; TLU, tropical livestock unit.

important demographic factor determining how vulnerable a household could be. For example, households headed by person above 50 years of age are more likely to be vulnerable compared with the younger persons. Consequently, elderly household heads are probably worse off in terms of preparing strategies to cushion their families against adverse climatic stresses and impacts and likely to make them more vulnerable. Similarly, the more dependents a household has the more likely for it to be vulnerable since a larger proportion of household resources are directed to dependents who cannot contribute much toward household welfare. Further results also show that widowed or divorced single-headed families are 37.4\% more likely to be vulnerable than families where both spouses are present. According to the study results, it was observed that livestock diversity had higher odds ratio of 29.592, which suggest that households with more than two livestock species are 28 times more likely to shift from highly vulnerability category to moderately vulnerability level.

Although 27 variables were hypothesized to be correlated with vulnerability, ordinal regression model result confirmed that only 17 factors were significant (at $p<0.1$ and $p<0.05$ ) in influencing households' vulnerability. Although not computed in this present study, it should be noted that different determinants have differential effects on a household's vulnerability levels.

\section{Discussion}

Drought was considered by the respondents as one of the most frequent hazards in Turkana, in addition to other hazards such as conflicts, disease outbreaks and flooding. The pastoralist respondents maintained that frequent, prolonged drought events have increased in severity over the past decade or so. This perception corroborate Nicholson's (2014) assertion about drought events 
Table 7 Factors influencing household's vulnerability

\begin{tabular}{|c|c|c|c|c|c|}
\hline Variables & Estimate & SE & OR & $z$ & $p$ value \\
\hline Sex of HH head: female & -1.3828 & 0.2303 & 0.2509 & -6.0049 & $<0.0001^{*}$ \\
\hline Age of $\mathrm{HH}$ head: $50+$ years & 1.5714 & 0.2704 & 4.8134 & 5.8106 & $<0.0001^{*}$ \\
\hline Experiences in the area: less than 5 years & -0.6187 & 0.399 & 0.5386 & -1.5506 & 0.1220 \\
\hline HH size: more than 5 persons & 2.2155 & 0.2651 & 9.1663 & 8.3585 & $<0.0001^{*}$ \\
\hline Educational level: no primary education & -0.1754 & 0.2684 & 0.8391 & -0.6534 & 0.5140 \\
\hline Dependents: more than 5 persons & 2.1434 & 0.2639 & 8.5281 & 8.1212 & $<0.0001^{*}$ \\
\hline Marital status: single (including divorced and widowed) & -0.4689 & 0.2349 & 0.6257 & -1.9965 & $0.0468^{*}$ \\
\hline Linkages: having no social linkages & 0.4232 & 0.2456 & 1.5268 & 1.7233 & $0.0859^{* *}$ \\
\hline Visit by extension officers: no access to extension services & -1.0717 & 0.2237 & 0.3424 & -4.7909 & $<0.0001^{*}$ \\
\hline Access to early warning information: having no access & -1.017 & 0.2535 & 0.3617 & -4.0119 & $<0.0001^{*}$ \\
\hline Non-farm income: $\mathrm{HH}$ with no farm income & 2.3332 & 0.2715 & 10.3108 & 8.5946 & $<0.0001^{*}$ \\
\hline Herd size in TLU: own less than 2 TLUs & -1.8785 & 0.3414 & 0.1528 & -5.502 & $<0.0001^{*}$ \\
\hline Herd structure: no milking herd & -0.668 & 0.2434 & 0.5128 & -2.7442 & $0.0064^{*}$ \\
\hline Distance to market: more than $10 \mathrm{~km}$ away & 0.7694 & 0.2301 & 2.1586 & 3.3442 & $<0.0001^{*}$ \\
\hline Property regime: own private land & 0.5666 & 0.375 & 1.7623 & 1.5111 & 0.1318 \\
\hline Access to remittances: no cash transfers & -0.2696 & 0.2161 & 0.7637 & -1.2477 & 0.2131 \\
\hline $\mathrm{HH}$ employed: no member of $\mathrm{HH}$ employed & -0.6226 & 0.3337 & 0.5365 & -1.866 & $0.0630^{* *}$ \\
\hline $\mathrm{HH}$ coping strategies: less than 2 coping strategies & -1.0896 & 0.4268 & 0.3363 & -2.5529 & $0.0112^{*}$ \\
\hline Livestock diversity: less than 2 livestock species & 3.3875 & 0.3506 & 29.592 & 9.663 & $<0.0001^{*}$ \\
\hline Credit access: having no access to credit at all & -1.1825 & 0.2703 & 0.3065 & -4.3753 & $<0.0001^{*}$ \\
\hline Mobility: able to move livestock freely & 1.2984 & 0.2424 & 3.6635 & 5.3571 & $<0.0001^{*}$ \\
\hline Temperature: experiencing increase & -0.0412 & 0.2175 & 0.9597 & -0.1892 & 0.8500 \\
\hline Drought: noticed increasing events & -0.2123 & 0.6269 & 0.8087 & -0.3387 & 0.7350 \\
\hline Flood: noticed change & -0.1252 & 0.5225 & 0.8823 & -0.2396 & 0.8108 \\
\hline Wind: noticed unusual change & -0.2462 & 0.3355 & 0.7818 & -0.7338 & 0.4636 \\
\hline $\mathrm{HH}$ facing more than 2 hazards in 5 years & -0.0369 & 0.2409 & 0.9638 & -0.1532 & 0.8784 \\
\hline
\end{tabular}

$\mathrm{SE}$, standard error; OR, odds ratio; $z$, score of two sample tests (basically a $t$ test) though using the standard normal to calculate the $p$ value and expressing the statistically significance levels at $* 5 \%$ and ${ }^{*} 10 \%$. (Source: Ordinal logistic regression model: single predictors).

in northern Kenya, with rainfall being at least $50 \%$ to $75 \%$ below normal in almost half of the drought-stricken region and is likely to be linked to changing climatic conditions within the greater Horn of Africa. However, there is a great deal of uncertainty and tension about when, where and how much climate change will happen. Even less is known about the actual impacts of these perceived changes (Kabubo-Mariara 2009; Notenbaert et al. 2013; Intergovernmental Panel on Climate Change IPCC 2014) to the dry land communities. It is argued that due to the frequency of shocks in the study area, adaptive or coping capacity and mechanisms adopted by vulnerable households could well have equal or larger ranges to that of exposure and sensitivity. As discussed earlier on vulnerability, the interaction of environmental (biophysical) forces determines exposures and sensitivities, and various social, cultural, political and economic forces shape adaptive capacity (Yohe and Tol 2002; Turner et al. 2003; Skjeflo 2013).
In the study area just like the rest of northern Kenya, pastoralist households largely bear the brunt of negative impacts of extreme climate events like drought, which include increased poverty, water scarcity, resource-based conflicts, disease outbreaks and food insecurity. The majority of people in Turkana live below the absolute poverty line (an estimated $87.5 \%$ of the population) with more than $50 \%$ heavily relying on food aid and safety net programmes from year to year. The people who are already poor in this remote part of the country are struggling to cope with the added burden of increasingly unpredictable weather, which is triggered by climate variability and change. Evidence shows that Turkana is constrained by the harsh climatic conditions and remoteness, coupled with poor infrastructure and low access to essential services (Republic of Kenya 2012) Previous studies (Thornton et al. 2006; Kabubo-Mariara 2009) in the region confirmed that it is becoming increasingly difficult for households to bounce back from ever-changing, inconsistent weather 
affecting their livelihoods, and many have been forced to pursue other livelihoods and coping mechanisms that only increase the cycle of vulnerability.

This study has shown that female-headed households, households with experience of less than 5 years in the area, household heads with no primary level of education and households headed by divorced and widowed persons, with no access to extension services and early warning information, in particular, are disproportionately likely to be affected by climate stresses and variability. In times of climate stresses and shocks like drought, these categories of households tend to have fewer options to find other ways of making a living, because their very low levels of literacy reduce their opportunities in coping mechanisms such as wage employment. Similarly, female or divorced and widowed household heads are likely not to be empowered enough in pastoral communities to make household decisions (Nabikolo et al. 2012) and are frequently without access to credit services and adequate capital assets or not able to own large herds to manage households' daily requirements. Similar observations have been made by Kakota et al. (2011) in Malawi and Tesso et al. (2012) in Ethiopia that widowed or divorced household heads are more vulnerable because they rely on income earned by either the father or mother as the bread winners. These findings make a strong case for continuous targeting of pastoralist women in resilience-building interventions in the rangelands.

The results are consistent with previous findings (Deressa et al. 2008) in similar ecosystems. However, for the biophysical variables, the greater the level of household reliance on natural resources, such as pastoralism or dry land crop farming, the greater will be their vulnerability to climate variability and change. This is partly because the use of such natural resources is dependent on rainfall, which is projected to change. This study observed that almost all the postulated biophysical/ environmental variables contribute positively to household vulnerability. It is likely that the level of dependence on natural resources especially pastures and water will vary from household to household. For example, while the majority of households (78.9\%) depend on livestock herding as their main source of livelihood, for others, livestock is just an equal or lesser contributor besides other economic activities.

The level of vulnerability is closely associated with the degree of poverty in Turkana. This county has higher degrees of vulnerability in terms of households' adaptive capacity or social and economic characteristics that are linked to their exposure and sensitivity to biophysical variables (Lo'pez-Carr et al. 2014). The findings of this study suggest that in case of an external stress or shock, the majority of the households would need some assistance for them to recover. These results reflect the findings of studies by Kenya National Bureau of Statistics (KNBS) (2013) which showed that Turkana is the poorest county in Kenya, with $87.5 \%$ of the population living in absolute poverty. Other studies have indicated that Turkana region has a number of households with high of dependents, low engagement in off-farm activities and low levels of education (Blench 2000; McPeak and Barrett 2001; Watson and van Binsbergen 2008).

The determinants of households' vulnerability were found to be significantly influenced by the sex of the household head, age of the household head, size of the household, number of dependents, marital status, social linkages, access to extension services and early warning information. In addition, non-farm income, herd size and diversity, herd structure and herd mobility, access to markets, households' employment status, coping strategies and access to credit were also observed to be the key determinants of the households' vulnerability to climate-induced stresses. This concurs with studies by Eriksen et al. (2005) and Notenbaert et al. (2013) which similarly observed some of these factors to be the key determinant of households' vulnerability to climate variability and change in rural communities. The results are also consistent with previous findings by Kakota et al. (2011) and Gebrehiwot and van der Veen (2013). From these findings, it seems there is still more to be done to understand vulnerability and its underlying processes. In this paper, the causal relationships between the statistically significant variables and outcomes in terms of vulnerability levels are explained using existing literature. Some of these explanations are, however, rather speculative and not confirmed for the local situation. More in-depth qualitative fieldwork, such as including open-ended questions, conducting focus-group discussions or in-depth interviews with selected households based on these factors, could strengthen our confidence in some of these explanations. The combination of quantitative surveys with qualitative autopsy is likely to provide a much more in-depth analysis of determinants of vulnerability.

\section{Conclusions}

Understanding vulnerability to environmental change and extreme climate events is necessary for policy makers to develop mitigation and adaptation programmes for long-term resilience. Vulnerability analyses contribute to the knowledge on climate-sensitive socio-economic or ecological systems, enabling policy to be targeted on the most vulnerable places, sectors or people and adaptation options to be defined. The results of this study from Turkana portray social and biophysical vulnerability indices which are useful to local development programming for long-term resilience. However, as a prerequisite for building households' resilience to climatic extremes, in-depth understanding is necessary of the adaptive capacity, exposure and sensitivity. 
This study focused on the micro-level to assess the variability of vulnerability across different households. Categorization of vulnerability levels was used to help identify households that are not vulnerable currently but have a high probability of becoming vulnerable in the future. In the future, studies assessing household-level vulnerability to climate-induced stresses should explore the use of panel data as well as cross-sectional data to portray longitudinal and cross-sectional characteristics of households. Similarly, future resilience interventions should target individual households within a community because major decisions about adaptation to climateinduced stresses and livelihood processes are taken at the micro-level.

We conclude that because of various social, economic and biophysical determinants observed to influence households' vulnerability to climate-induced stresses, policies with emphasis on women's empowerment, promoting education, supporting extension services and enhancing diversifications of income sources and access to credit, supporting herd mobility and diversity, creating employments, and increasing access to markets and early warning information are likely to improve resilience of pastoral households. Although the results of this study are specific to Turkana County in Kenya, the approach and findings could be applicable to other arid and semi-arid areas in the region.

\section{Endnotes}

${ }^{\mathrm{a}} \mathrm{A}$ TLU is the $250-\mathrm{kg}$ live weight of any domestic herbivore (sheep or goat $=0.1$ TLU; donkey $=0.4$ TLU; cattle $=0.7$ TLU; camel = $1.0 \mathrm{TLU}$ ).

\section{Competing interests}

The authors declare that they have no competing interests.

\section{Authors' contributions}

FEOO collected the data and drafted the manuscript. OWW and MN guided the design of the research study and provided technical reviews of the paper. All authors read and approved the final manuscript.

\section{Authors' information}

FEOO is a PhD research student in the Department of Land Resource Management and Agricultural Technology (LARMAT), University of Nairobi, Kenya and a project officer of the United Nations Development Programme (UNDP), Dryland Development Centre United Nations Office in Nairobi, Kenya. OWW is a lecturer at LARMAT, University of Nairobi and a post-doctoral research fellow at the German Institute for Tropical and Sub-tropical Agriculture (DITSL), Germany, while MMN is a senior lecturer at LARMAT, University of Nairobi.

\section{Acknowledgements}

The work has been supported by small grants from the African Climate Change Fellowship Program, Global Change for System Analysis, Research \& Training (ACCFP/START), and additional support from the Red Cross/Red Crescent Climate Centre/START and United Nations International Strategy for Disaster Reduction (UNISDR) under Climate and Development Knowledge Network small grant. The authors also thank Boniface Makone of the Welcome Trust for the statistical guidance during the preparation of this paper.

\section{Author details}

'Department of Land Resources Management and Agricultural Technology, University of Nairobi, P.O. Box 29053, Kabete, Nairobi 00625, Kenya. ²Dryland Development Centre, United Nations Development Programme (UNDP), United Nations Office in Nairobi, P.O. Box 30552, Nairobi, Gigiri 00100, Kenya. ${ }^{3}$ German Institute for Tropical and Subtropical Agriculture (DITSL), Steinstraße 19, Witzenhausen 37213, Germany.

Received: 15 April 2014 Accepted: 18 June 2014

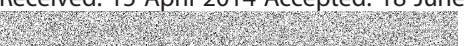

\section{References}

Adger, WN, and PM Kelly. 1999. Social vulnerability to climate change and the architecture of entitlements. Mitigation and Adaptation Strategies for Global Change 4:253-266.

Adger, WN. 1999. Social vulnerability to climate change and extremes in coastal Vietnam. World Development 27:249-269.

Adger, WN. 2006. Vulnerability. Global Environmental Change 16(3):68-281.

Blench, R. 2000. Extensive pastoral livestock systems: Issues and options for the future. GCP/JPN/005/ JPN. Rome, Italy: FAO (Food and Agriculture Organization of the United Nations).

Brooks, N, WN Adger, and PM Kelly. 2005. The determinants of vulnerability and adaptive capacity at the national level and the implications for adaptation. Global Environmental Change 15(2):151-163.

Callaway, JM. 2004. Adaptation benefits and costs:how important are they in the global policy picture and how can we estimate them? Global Environmental Change 14:273-284

Carpenter, S, B Walker, JM Anderies, and N Abel. 2001. From metaphor to measurement: resilience of what to what? Ecosystems 4(8):765-781.

Deressa, T, RM Hassan, and C Ringler. 2008. Measuring Ethiopian farmers' vulnerability to climate change across regional states, IFPRI discussion paper no. 806.

Eriksen, S, and K O'Brien. 2007. Vulnerability, poverty and the need for sustainable adaptation measures. Climate Policy 7:337-352.

Eriksen, S, K Brown, and K Mick. 2005. The dynamics of vulnerability:locating coping strategies in Kenya and Tanzania. Geographical Journal 171:287-305

Fraser, EDG, AJ Dougill, K Hubacek, CH Quinn, J Sendzimir, and M Termansen. 2011. Assessing vulnerability to climate change in dryland livelihood systems: Conceptual challenges and interdisciplinary solutions. Ecology and Society 16(3):14

Füssel, H. 2007. Vulnerability:a generally applicable conceptual framework for CC research. Global Environmental Change 17:155-167.

Gallopın, GC. 2006. Linkages between vulnerability, resilience, and adaptive capacity. Global Environmental Change 16:293-303.

Gebrehiwot, T, and A van der Veen. 2013. Climate change vulnerability in Ethiopia:disaggregation of Tigray Region. Journal of Eastern African Studies 7 (4):607-629.

Greene, WH. 1997. Econometric analysis. New Jersey:Prentice Hall.

Hendrickson, D, J Armon, and R Mearns. 1998. The changing nature of conflict and famine vulnerability: the case of livestock raiding in Turkana District, Kenya. Disasters 22:185-199.

Herrero, M, C Ringler, J van de Steeg, P Thornton, T Zhu, E Bryan, A Omolo, J Koo, and A Notenbaert. 2010. Climate variability and climate change and their impacts on Kenya's agriculture sector. Nairobi, Kenya: International Livestock Research Institute (ILRI)

Hewitt, K. 1995. Excluded perspectives in the social construction of disaster. International Journal of Mass Emergencies and Disasters 13:317-319.

Hinkel, J. 2011. Indicators of vulnerability and adaptive capacity: towards a clarification of the science-policy interface. Global Environmental Change 21:198-208.

Household Economy Approach (HEA). 2012. Livelihood profiles:Six livelihood zones in Turkana County, Kenya. June 2012 report prepared for Oxfam and Save the Children UK.

Intergovernmental Panel on Climate Change IPCC. 2001. Climate change 2001: Impacts, adaptations and vulnerability. Report of working group II. Synthesis report. Cambridge: Cambridge University Press.

Intergovernmental Panel on Climate Change IPCC. 2012. Managing the risks of extreme events and disasters to advance climate change adaptation. A special report of Working Groups I and II of the Intergovernmental Panel on Climate Change. Cambridge, UK: Cambridge University Press. 
Intergovernmental Panel on Climate Change IPCC. 2014. Climate change: Impacts, adaptation, and vulnerability. Working Group II contribution to the IPCC 5th assessment report.

Jaetzold, R, and H Schmidt. 1983. Farm management in Kenya, vol. II part C: East Kenya. Nairobi, Kenya: Ministry of Agriculture.

Kabubo-Mariara, J. 2009. Global warming and livestock husbandry in Kenya: impacts and adaptations. Ecological Economics 68:1915-1924.

Kakota, T, D Nyariki, D Mkwambisi, and W Kogi-Makau. 2011. Gender vulnerability to climate variability and household food insecurity. Climate and Development 3(4):298-309.

Kasperson, J, R Kasperson, and B Turner (eds). 1995. Regions at Risk: Comparisons of Threatened Environments. New York: United Nations University Press.

Kelly, PM, and WN Adger. 2000. Theory and practice in assessing vulnerability to climate change and facilitation adaptation. Climatic Change 47(4):925-1352.

Kenya National Bureau of Statistics (KNBS). 2013. Exploring Kenya's inequality: Pulling apart or pooling together. Nairobi, Kenya: National Bureau of Statistics and Society for International Development (SID). National report ISBN-9789966-029-17-1.

Klein, RJ, S Eriksen, LO Naess, A Hammill, TM Tanner, C Robledo, and K O'Brien. 2007. Portfolio screening to support the mainstreaming of adaptation to climate change into development assistance, Tyndall Centre Working Paper No. 102.

Liverman, DM. 1990. Vulnerability to global environmental change. In Understanding global environmental change, ed. RE Kasperson et al., 27-44. Worcester:Center for Technology, Environment, and Development, Clark University.

Lo'pez-Carr, D, GP Narcisa, EA Juliann, MM Jankowska, C Funk, G Husak, and J Michaelsen. 2014. A spatial analysis of population dynamics and climate change in Africa: potential vulnerability hot spots emerge where precipitation declines and demographic pressures coincide. Population Environment 35:323-339.

Madu, IA. 2012. Partial vulnerability of rural households to climate change in Nigeria:Implication for internal security. Working paper number 2; May 2012. University of Texas, USA: The Robert S. Strauss Center for International Security and Law.

Marshall, NA, CJ Stokes, NP Webb, PA Marshall, and AJ Lankester. 2014. Social vulnerability to climate change in primary producers: a typology approach. Agriculture, Ecosystems and Environment 186:86-93.

McCabe, JT, R Dyson-Hudson, PW Leslie, PH Fry, N Dyson-Hudson, and J Wienpahl. 1988. Movement and migration as pastoral responses to limited and unpredictable resources. In Arid lands today and tomorrow, ed. EE Whitehead, CF Hutchinson, BN Timmerman, and RG Varady, 727-734. Tucson, Arizona, USA: Proceedings of an International Research and Development Conference.

McCarthy, JJ, OF Canziani, NA Leary, DJ Dokken, and KS White (eds.). 2001. Climate change 2001: Impacts, adaptation and vulnerability. Cambridge: Cambridge University Press.

McPeak, JG, and CB Barrett. 2001. Differential risk exposure and stochastic poverty traps among east African pastoralists. American Journal of Agricultural Economics 83(3):674-679.

Nabikolo, D, B Bashaasha, MN Mangheni, and JGM Majaliwa. 2012. Determinants of climate change adaptation among male and female headed farm households in eastern Uganda. African Crop Science Journal 20(2):203-212.

National Drought Management Authority - NDMA. 2013. Turkana County drought monitoring and early warning bulletin - December 2013.

Nicholson, SE. 2014. A detailed look at the recent drought situation in the Greater Horn of Africa. Journal of Arid Environments 104:71-79.

Notenbaert, A, SN Karanja, M Herrero, M Felisberto, and S Moyo. 2013. Derivation of a household-level vulnerability index for empirically testing measures of adaptive capacity and vulnerability. Regional Environmental Change 13:459-470.

Opiyo, FEO, SM Mureithi, and RK Ngugi. 2011. The influence of water availability on pastoralist's resource use in Kitui and Mwingi districts of Kenya. Journal of Human Ecology 35(1):43-52.

Paavola, J. 2008. Livelihoods, vulnerability and adaptation to climate change in Morogoro, Tanzania. Environmental Science and Policy 11(7):642-654.

Pearson, L, R Nelson, S Crimp, and J Langridge. 2008. Climate change vulnerability assessment: Review of agricultural productivity. CSIRO climate adaptation flagship working paper 08.1.

Pulwarty, RS, and WE Riebsame. 1997. The political ecology of vulnerability to hurricane-related hazards. In Hurricanes: Climate and socioeconomic impacts, 185-214. Berlin, Heidelberg, New York: Springer.
Republic of Kenya. 2012. National policy for sustainable development of Northern Kenya and other arid lands; Sessional Paper No. 8 of 2012, Republic of Kenya.

Schilling, J, FEO Opiyo, and J Scheffran. 2012. Raiding pastoral livelihoods: Motives and effects of violent conflict in north-western Kenya. Pastoralism: Research, Policy and Practice 2:25.

Sherwood, A. 2013. Community adaptation to climate change: exploring drought and poverty traps in Gituamba location, Kenya. Journal of Natural Resources Policy Research 5(2-3):147-161.

Silvestri, S, E Bryan, C Ringler, M Herrero, and B Okoba. 2012. Climate change perception and adaptation of agro-pastoral communities in Kenya. Regional Environmental Change 12(4):791-802.

Skjeflo, S. 2013. Measuring household vulnerability to climate change-Why markets matter? Global Environmental Change 23(6):1694-1701.

Stringer, LC, MS Reed, AJ Dougill, and C Twyman. 2009. Local adaptations to climate change, drought and desertification: Insights to enhance policy in southern Africa. Environmental Science and Policy 12:748-765.

Tesso, G, B Emana, and M Ketema. 2012. Analysis of vulnerability and resilience to climate change induced shocks in North Shewa, Ethiopia. Agricultural Sciences 3:871-888.

Thomas, RJ. 2008. Opportunities to reduce the vulnerability of dryland farmers in Central and West Asia and North Africa to climate change. Agriculture, Ecosystems and Environment 126(1-2):36-45.

Thornton, PK, PG Jones, T Owiyo, RL Kruska, M Herrero, P Kristjanson, A Notenbaert, N Bekele, A Omolo, and with contributions from Orindi V, B Otiende, A Ochieng, S Bhadwal, K Anantram, S Nair, V Kumar, and U Kulkar. 2006. Mapping Climate Vulnerability and Poverty in Africa, 171. Nairobi, Kenya: Report to the Department for International Development, International livestock research institute.

Turner, BL, RE Kasperson, PA Matson, JJ McCarthy, RW Corell, L Christensen, N Eckley, JX Kasperson, A Luers, ML Martello, C Polsky, A Pulsipher, and A Schiller. 2003. A framework for vulnerability analysis in sustainability science. Proceedings of the National Academy of Sciences of the United States of America 100(14):8074-8079

United Nations International Strategy for Disaster Reduction-UNISDR. 2009. Global assessment report on disaster risk reduction, 207. 207:207.

United Nations. 2004. Living with risk: A global review of disaster reduction initiatives. Geneva, Switzerland: United Nations International Strategy for Disaster Reduction.

UN-OCHA. 2011. Horn of Africa Crisis: Situation Report No. 13: United Nations Office for Co-ordination of Humanitarian Affairs.

Watson, DJ, and J van Binsbergen. 2008. Livestock market access and opportunities in Turkana, Kenya. ILRI Research Report 3, 106. Nairobi, Kenya: ILRI (International Livestock Research Institute).

Yohe, G, and RSJ Tol. 2002. Indicators for social and economic coping capacity - moving toward a working definition of adaptive capacity. Global Environmental Change 12:25-40.

Yuga, NG, PG Shivakoti, and RP Sylvain. 2010. Household-level vulnerability to drought in hill agriculture of Nepal: Implications for adaptation planning. International Journal of Sustainable Development and World Ecology 17(3):225-230.

doi:10.1186/s13570-014-0010-9

Cite this article as: Opiyo et al:: Measuring household vulnerability to climate-induced stresses in pastoral rangelands of Kenya: Implications for resilience programming. Pastoralism: Research, Policy and Practice 2014 4:10. 